\title{
New developments in intrauterine device use: focus on the US
}

\author{
Anita L Nelson' \\ Natasha Massoudi ${ }^{2}$ \\ 'Department of Obstetrics and \\ Gynecology, Los Angeles BioMedical \\ Research Institute at Harbor-UCLA \\ Medical Center, David Geffen School \\ of Medicine at UCLA, Torrance, \\ CA, USA $;{ }^{2}$ American University of \\ the Caribbean School of Medicine, \\ Cupecoy, Sint Maarten
}

This article was published in the following Dove Press journal:

Open Access Journal of Contraception

13 September 2016

Number of times this article has been viewed

Correspondence: Anita L Nelson

1457, Third Street, Manhattan Beach, CA 90266, USA

$\mathrm{Tel}+\mathrm{I} 3109377226$

Fax + I 310937 I416

Email anitalnelson@earthlink.net
Abstract: Many more women in the US today rely upon intrauterine devices (IUDs) than in the past. This increased utilization may have substantially contributed to the decline in the percentage of unintended pregnancies in the US. Evidence-based practices have increased the number of women who are medically eligible for IUDs and have enabled more rapid access to the methods. Many women enjoy freedom to use IUDs without cost, but for many the impact of the Affordable Care Act has yet to be realized. Currently, there are three hormonal IUDs and one copper IUD available in the US. Each IUD is extremely effective, convenient, and safe. The newer IUDs have been tested in populations not usually included in clinical trials and provide reassuring answers to older concerns about IUD use in these women, including information about expulsion, infection, and discontinuation. On the other hand, larger surveillance studies have provided new estimates about the risks of complications such as perforation, especially in postpartum and breastfeeding women. This article summarizes significant features of each IUD and provides a summary of the differences to aid clinicians in the US and other countries in advising women about IUD choices.

Keywords: copper intrauterine device, levonorgestrel intrauterine systems, noncontraceptive benefits, same-day/quick start initiation, safety, bleeding patterns, placement pain, medical eligibility

\section{Introduction}

Even though intrauterine devices (IUDs) are used by more than 168 million women worldwide - making IUDs the most commonly used method of reversible female contraception - the use of IUDs in the US has lagged significantly. ${ }^{1}$ However, the utilization of IUDs and implants expanded between 2009 and 2012 from 8.5\% to $11.6 \%$ among women who use contraception. ${ }^{2}$ During that time (2008-2012), unintended pregnancy rates in the US declined for the first time in decades. ${ }^{3}$ This renewed interest in IUDs stands in stark contrast to what had happened after 1986 when IUDs were very unpopular in the wake of the Dalkon Shield lawsuits. ${ }^{4-6}$ The introduction of the most effective copper IUD in 1988 (ParaGard Copper T [CuT]-380A IUD) was not only delayed for 3 years but was also done with extreme caution and utilized extensive contraindications. The levonorgestrel-releasing intrauterine system (LNG-IUS $20 \mu \mathrm{g} / 24 \mathrm{~h}$; Mirena; Bayer Healthcare Pharmaceuticals, Whippany, NJ, USA) was available in Europe for more than a decade before it came to the US in 2000.

Several important developments have recently spurred the adoption of IUDs. The CHOICE study in St Louis, MO, USA, redefined the potential for both IUDs and 
implants. ${ }^{7,8}$ By stripping away cost as a barrier and by providing careful counseling, the researchers showed that more than three-quarters of a select population of women of all ages and parities chose to use IUDs and implants. Importantly, the CHOICE study also showed that even within the context of a clinical study, the pregnancy rates with oral contraceptives, patches, and vaginal ring were 20 times higher than those for IUDs or implants. ${ }^{8}$ Other large-scale projects, such as the Colorado Initiative, which provided IUDs and implants to adolescent and young women free of cost, demonstrated high acceptance and continuation rates for those methods. ${ }^{9}$

Practice guidelines have changed in response to new evidence about the safety of IUDs. ${ }^{10-13}$ More women are being identified as candidates for intrauterine contraceptives. Professional organizations have endorsed IUDs as first-line contraceptive options for sexually active teens in some countries. ${ }^{14,15}$ Those same new practice recommendations have also streamlined access to these devices. ${ }^{12,13}$ The US Affordable Care Act, which will eventually require all insurance companies to provide all forms of contraception without co-payments, has improved access to IUDs for many, but not all, women. ${ }^{16}$ Providing IUDs following elective abortion in lieu of delaying their placement until a return visit has been shown to result in higher rates of IUD use at 6 months ${ }^{17,18}$ and reduced rates of rapid repeat abortion. ${ }^{18}$ Similarly, immediate postpartum initiation of IUDs has been shown to be safe and effective, even in women who plan to breastfeed. ${ }^{19-21}$ In some states in the US, the public sector Medicaid programs now pay for both the supplies and the professional fees for immediate postpartum placement of IUDs and implants. Early studies demonstrating that the copper IUD is the most effective form of emergency contraception (EC) have spurred new research into that potential application. ${ }^{22}$ The profound impact that the original LNG-IUS 20 had on endometrial growth has led to widespread use of the device for the treatment of heavy menstrual bleeding, and more recently, as the treatment of endometrial hyperplasia ${ }^{23}$ and experimentally to reverse early-stage endometrial carcinoma. ${ }^{24}$ Although off-label in the US, the LNG-IUS can be used for endometrial protection during postmenopausal estrogen therapy. ${ }^{25}$

During most of this period of growth of IUDs in the US, there have been only two intrauterine contraceptives available. Those IUDs differed primarily in the bleeding patterns that could be expected with their use; hence, counseling was reasonably straightforward. With the growing popularity of IUSs, two new LNG-IUSs have been developed to provide new options either by reducing the size of the IUD and its hormonal content or by reducing its cost. ${ }^{26}$ Other innovative
IUDs are in various stages of development and clinical testing. With all these options for IUDs, it becomes more challenging for clinicians to know how best to help women select IUDs that would best meet their individual needs. In addition, it becomes important to understand the differences among them to effectively advocate for third-party payors to provide coverage for the different IUDs.

This article summarizes recent developments that have been shown to increase access to all IUDs and describes the features of each of the IUDs currently available in the US, as well as what is known of others that may become available in the near future. Even with the impressive recent growth seen in IUD use, potential complications with IUD placement still can occur, and hence updates on approaches to reduce those IUD-related problems are also discussed. It is better understood today that women still have profound concerns about the safety and appropriateness of birth control. This review summarizes recent findings about women's attitudes to help readers develop more effective contraceptive counseling techniques.

\section{Recognition of candidates for IUDs}

The World Health Organization Medical Eligibility Criteria (WHO-MEC) and the US Centers for Disease Control and Prevention MEC (US MEC) differentiate only between "LNG IUDs" and "copper IUDs". ${ }^{10,11}$ Definitions of these categories are presented in Table 1 . They report that virtually every medical condition is either category 1 or category 2 for either group of IUDs. The only category 4 conditions for IUD placement are pregnancy, cervical/uterine/pelvic infection or cancer (cervical or endometrial), distorted uterine cavities, and undiagnosed abnormal uterine bleeding. Current breast cancer is also a category 4 condition for LNG-IUS use. The hormonal IUDs have been rated as category 3 choices for initiation in women with systemic lupus erythematosus (unless they are negative for antiphospholipid antibodies), ischemic heart disease, severe (decompensated) liver cirrhosis, benign or malignant liver tumors, complicated solid organ transplants, history of breast cancer, gestational trophoblastic

Table I Categories of medical eligibility by the WHO and Centers for Disease Control and Prevention

\begin{tabular}{ll}
\hline Category & Definition \\
\hline I & No restriction (method can be used) \\
2 & Advantages generally outweigh theoretical or proven risks \\
3 & Theoretical or proven risks usually outweigh the \\
4 & advantages \\
\hline
\end{tabular}

Abbreviation: WHO, World Health Organization. 
disease, and some AIDS therapies. The copper IUD is considered a category 3 choice for initiation in women with solid organ transplants, systemic lupus erythematosus with severe thrombocytopenia, gestational trophoblastic disease, and pelvic tuberculosis. Product labeling lists many more absolute and relative contraindications to IUD use. Although product labeling may not dictate practice, it is always prudent at least to acknowledge the existence of listed contraindications when counseling women so that they will not worry that an error has been made.

\section{Streamlining initiation of IUDs}

The CDC's Selective Practice Recommendations for Contraception, 2013, parallel the WHO 2014 document in providing detailed guidance (and supporting evidence) to enable more widespread and timely access to IUDs. ${ }^{12,13}$ These recommendations separate the services a woman might need for ongoing well-women care from the services she needs to initiate the use of her desired contraceptive method. They also minimize the testing needed before that initiation. For a woman whose medical history does not indicate that she has any category 4 or concerning category 3 conditions, all that is required to complete the evaluation of her candidacy for IUD use is a speculum examination to rule out potential active infection and a bimanual examination to rule out infection and pelvic masses. Same-day/quick start placement (placing an IUD at any time in the woman's cycle that the clinician can be reasonably certain that she is not pregnant) is not associated with an increase in rates of pelvic inflammatory disease (PID). ${ }^{27}$ Even for women whose tests for gonorrhea or chlamydia obtained on the day IUD placement returned positive, PID rates were $<1 \%$ if they were treated within 1 week of IUD placement. ${ }^{28}$ On the other hand, failure to provide same-day placement had serious consequences; delaying initiation of IUDs or implants in the CHOICE study increased unintended pregnancy rates by $60 \%$ compared to same-day initiation. ${ }^{28}$

\section{Procedurally related issues common to all IUDs}

Uterine size, mobility, and position must be accurately assessed to minimize risks of perforation and expulsion; usually bimanual examination is sufficient. For women with higher body mass indices or generous abdominal padding, estimation of uterine size can be challenging on a bimanual examination. However, if examining fingers are introduced into both the woman's vagina and deep into her rectum and the abdominal examining hand is used to press her uterus against the rectal examining finger, the clinician can often estimate very accurately both the size and position of the woman's uterus. Ultrasound imaging should not be needed except in special circumstances, such as to evaluate the potential for significant endometrial distortion by leiomyoma. If ultrasound imaging is not easily available to assess the adequacy of the fundus to accommodate the IUD arms, the size of that space can be estimated by pivoting the uterine sound from side to side when it reaches the fundus.

\section{Pain reduction measures: instrumentation}

Women may experience discomfort and occasionally severe pain during IUD placement and for several minutes following the completion of the procedure. Gentle technique and verbal reassurance can help relax a woman to reduce her anxiety and her perception of pain. Special instruments can also help. For example, for women with normal pelvic support, using a shorter bladed speculum may reduce the patient's baseline pressure sensation. Similarly, if the traditional cervical tenaculum with thick, overlapping pincers is replaced with a tenaculum with thin tips that meet in the midline, but do not overlap, both pain with placement of the tenaculum and bleeding that occurs after its removal may diminish. Other devices may also help. ${ }^{29}$ Placement of the tenaculum on the cervical lip that is further away from the introitus optimally straightens the uterine axis when traction is applied. If cervical stenosis is encountered, use of cervical os finders in place of traditional metal dilators is very effective in progressively dilating the cervix.

\section{Pain reduction measures: medications}

Despite extensive study, there is little that has been found to significantly reduce pain scores associated with IUD placement. Fortunately most studies have found that median pain scores are relatively low (eg, VAS 3/10). ${ }^{30,31}$ Often, it is difficult to compare the interventions to reduce pain because different studies measure pain perceptions at different times; not all studies distinguish pain with IUD placement itself from post-procedure cramping pain. Three interventions have been most extensively studied: nonsteroidal anti-inflammatory agents (NSAIDs), lidocaine, and misoprostol. NSAIDs given orally or administered intramuscularly prior to the procedure have been found by most investigators to reduce pain from cramping after placement, but not to substantially reduce pain scores during the actual placement. ${ }^{32,33}$ However, overall pain scores in some studies were reported to be lower with NSAIDs, especially when they were combined with other agents, such as paracervical block. ${ }^{34,35}$ 
Variable success has been reported with lidocaine gels, sprays, injections, and infusions; topical application of $2 \%$ lidocaine gels did not reduce pain with tenaculum placement, but $1 \%$ lidocaine given as paracervical block did reduce that pain. ${ }^{36}$ Pain scores for IUD placement were not reduced by $2 \%$ lidocaine gel. ${ }^{37}$ However, in parous women, a $10 \%$ lidocaine spray did reduce median pain scores. ${ }^{38}$ Infusion of 2\% lidocaine liquid into the endometrial cavity did not reduce pain scores immediately following IUD placement. ${ }^{39}$ Newer lidocaine formulations may have beneficial impacts; use of $4 \%$ lidocaine administered with an adhesive matrix reduced pain scores in nulliparous women, but added significantly to the procedure time.$^{40}$ Lidocaine combined with prilocaine cream also showed lower scores when pain was measured at 10 minutes and 30 minutes after IUD placement. ${ }^{41}$

Misoprostol had earlier been advocated to soften the cervix, to ease IUD placement, and to reduce pain, but a meta-analysis showed higher mean pain scores for misoprostol than for placebo. ${ }^{42}$ Double-blinded studies showed no improvement in IUD placement rates, but higher rates of adverse side effects, even when misoprostol was combined with NSAIDs. ${ }^{31,43}$

Patient maneuvers, such as lower extremity muscle tensing, can be very helpful in preventing acute hypotension and vasovagal reactions during IUD placement procedures. ${ }^{43,44}$

\section{IUDs currently available in the US}

Currently, there are four US Food and Drug Administration (FDA)-approved IUDs available in the US - one copperreleasing IUD and three LNG-releasing IUDs. All utilize plastic T-shaped polyethylene frames with limited (5-minute) memory. The largest distinctions are between the copper and progestin IUDs (Table 2). Outside the US, other inert and metal IUDs are available. Copper surface areas for most of those IUDs vary from $200 \mathrm{~mm}^{2}$ to $375 \mathrm{~mm}^{2}$. Nickel and other metallic-coated IUDs have been offered in the People's Republic of China for decades, but those units are being phased out and replaced by more modern IUDs. None of the ex-US IUDs are discussed here.

\section{Copper-releasing IUD Description}

In the US, the only copper-releasing IUD is the CuT-380A IUD (ParaGard; Teva Pharmaceutical Industries Ltd., Sellersville, PA, USA). It contains $380 \mathrm{~mm}^{2}$ copper surface area supplied by a sleeve of solid copper on each of the arms (together $32 \mathrm{~cm}$ in width) and wrapped by a copper wire along the $36 \mathrm{~mm}$ vertical stem. Monofilament polyethylene thread is tied through the base creating two white tailstrings measuring $10.5 \mathrm{~cm}$ in length to facilitate detection and removal of the device. The CuT-380A IUD is designed to be used in women whose uterine cavities sound to a depth of 6-9 cm. ${ }^{45}$ It is approved by the FDA for use for up to 10 years, but many large family planning organizations routinely allow 12 years of use before recommending removal. One study demonstrated in a small group of women that this IUD could provide effective contraception for 20 years ${ }^{46}$ The useful life of this IUD should consider the woman's age at the time she had it placed. For example, one author recommended limiting the effective life of this copper IUD to 12 years if the woman was aged 25-35 years when she had it placed; women aged 35 years or older at the time of placement were eligible to continue using the IUD until they underwent menopause. ${ }^{47}$

The CuT-380A IUD is placed into the uterus using a two-handed technique. The IUD arms are loaded manually pointing downward into the insertion tubing after uterine sounding has verified that the woman's uterus is in the appropriate depth $(6-9 \mathrm{~cm})$. The loaded IUD tubing should be advanced directly in one step to the uterine fundus, and then the arms are to be released. With this approach, the WHO quoted a perforation rate of $0.6 / 1,000$ placements. ${ }^{47} \mathrm{~A}$ more recent European Surveillance study reported that perforation rates with the copper IUDs are lower than those with the LNG-IUS. ${ }^{48}$ However, because "perforation" included both embedment (partial perforation) and complete perforation through the uterine wall, the rate was higher than 1.1/1,000 women (95\% confidence interval [CI]: 0.7-1.7). This study was large enough (61,448 women followed up for $>6$ years) to quantify that the risk of uterine perforation for any IUD

Table 2 Description of IUD per FDA product

\begin{tabular}{|c|c|c|c|c|}
\hline & Mirena $^{\circledR}$ & Liletta/Levosert $^{\circledR}$ & Skyla/Jaydess $^{\circledR}$ & ParaGard $^{\circledR}$ \\
\hline Hormone & LNG & LNG & LNG & None \\
\hline Active ingredient (dose) & $52 \mathrm{mg}$ LNG & $52 \mathrm{mg}$ LNG & $13.5 \mathrm{mg}$ LNG & $380 \mathrm{~mm}^{2}$ copper \\
\hline LNG (mg)/released 24 hours (first year) & 20 & 18.6 & 8 & - \\
\hline Frame size & $32 \mathrm{~mm} \times 32 \mathrm{~mm}$ & $32 \mathrm{~mm} \times 32 \mathrm{~mm}$ & $28 \mathrm{~mm} \times 30 \mathrm{~mm}$ & $32 \mathrm{~mm} \times 36 \mathrm{~mm}$ \\
\hline String color & Brown & Blue & Brown & White \\
\hline Effective life - FDA labeling & 5 years & 3 years & 3 years & 10 years \\
\hline
\end{tabular}

Abbreviations: FDA, US Food and Drug Administration; IUD, intrauterine device; LNG, levonorgestrel. 
was sixfold higher in women who were breastfeeding. ${ }^{49}$ Being within 36 weeks of delivery also increased the risk of perforation, independent of breastfeeding status. ${ }^{49}$ Importantly, the authors found that none of the perforations lead to serious illness or to injury of abdominal or pelvic structures. To some extent, this may be surprising because the copper released from the IUD creates dense intraperitoneal adhesions. ${ }^{50}$

\section{Candidates}

As a nonhormonal method, the CuT-380A IUD can be used by women who have medical contraindications to progestogens (hepatic dysfunction progestin-sensitive tumors) and those who prefer to avoid use of synthetic hormones. Interestingly, conditions that were initially listed as contraindications to the use of the CuT-380A IUD when it was launched in 1988 are now ones for which the copper IUD is preferred. For example, in the wake of deep concerns for the infectious potential of IUD use in the 1980s, conditions that reduced a woman's ability to fight infection (eg, diabetes, chemotherapy, and steroid use) were listed in the original labeling as contraindications. Currently, we recognize that the copper IUD may be the best choice for women with these serious health problems, because it offers excellent pregnancy protection without exposing users to exogenous hormones and because the risk of pelvic infection is so low.

\section{Mechanisms of action}

This is a very important issue for many potential candidates and many clinicians. The mechanism of action of the copper IUD was difficult to elucidate, but convincing evidence shows that, as an ongoing method, it functions as a contraceptive (inhibiting fertilization). When copper IUD users are followed up with serial serum tests for beta human chronic gonadotropin levels, they show no temporary increase in that hormone, which would indicate implantation and loss. ${ }^{49}$ Many critics have voiced concern that the intense inflammatory changes induced in the endometrium could destroy fertilized ova or block implantation following fertilization. ${ }^{51}$ Several lines of investigation showed no support for any such postfertilization (interceptive) activity. Flushing of the uterine cavity on cycle days 20-21 did not yield blastocysts. ${ }^{52}$ Ova retrieved at the time of tubal sterilization performed following timed intercourse midcycle showed no normal division of the ova, which might have indicated union of the gametes..$^{53}$ On the other hand, the inflammatory changes in the endometrium do have spermicidal activity. ${ }^{54,55}$ In vitro, copper ions in concentrations typical of those found within the endometrial cavity with the CuT-380A IUD inhibit sperm motility and block activation of acrosomal enzymes in the sperm head needed for the sperm to penetrate through the zona pellucida to enable union of the gametes. ${ }^{56}$ These observations lead to the characterization of copper IUDs used for ongoing pregnancy prevention as "functional spermicides".

\section{Efficacy}

Cumulative failure rates in clinical trials as reported in package labeling are $0.7 \%$ (first year), $1.3 \%$ (fourth year), and $2.1 \%$ (tenth year). ${ }^{47}$ No pregnancy was observed after 8 years of use. ${ }^{47}$ In a comparative 7-year trial of parous women, the cumulative pregnancy rate with the CuT-380A was $2.45 \%$, but no further pregnancies occurred from 8 years to 11 years. ${ }^{57} \mathrm{~A}$ 12-year WHO international trial found that annual pregnancy rates were $\leq 0.4 / 100$ women-years and again no pregnancies occurred after the eighth year. ${ }^{58}$ In another analysis, the CuT$380 \mathrm{~A}$ IUD has been recognized as one of the most effective 5 -year methods with a failure rate of $0.3 \%-0.6 \%{ }^{59}$ In the most recent European Active Surveillance Study for IUDs, $>30$ copper IUDs were studied. First-year Pearl Index for these copper IUDs as a group was 0.52 (95\% CI: 0.42-0.64) with ectopic pregnancy ratios of $15 \%{ }^{60}$

\section{Discontinuation rates}

In the original US clinical trials, 2-year cumulative discontinuation rate for the CuT-380A IUD was $22 \%$, by 3 years that figure rose to $33 \%$ and it was $60 \%$ after 5 years. ${ }^{47}$ The CHOICE study found that at 24 months, 48 months, and 60 months, $23 \%, 35.8 \%$, and $44.1 \%$, respectively, of copper IUD users, respectively, had discontinued use of their method. ${ }^{7}$ In international studies, one-quarter to one-third of women used the device for the entire 10 years. ${ }^{61,62}$ Among HIV-infected women in Uganda, the first-year discontinuation rate was $8.6 \%{ }^{63}$

\section{Side effects}

Bleeding pattern abnormalities and dysmenorrhea are the most frequent reasons for removal requests. In the first year, $4 \%-15 \%$ of women had removed the CuT-380A IUD for these reasons. ${ }^{47}$ Studies have shown that for most women, blood loss increases by $30 \%-50 \%$ with the copper IUD, and this increase persists for the duration of the IUD use. In the first 9 weeks, two-thirds of participants reported increased menstrual blood loss (MBL); this percentage declined gradually to $48 \%$ at 12 months. $^{64}$

One large analysis found that in the first 9 weeks, $38 \%$ of women reported increased menstrual pain with the IUD, but $25 \%$ reported less pain than before the IUD. ${ }^{65}$ Throughout the study, approximately one-third of women continued to report increased menstrual pain. ${ }^{65}$ Intermenstrual spotting affected approximately one in four women; that prevalence 
did not change over time, but the mean number of days was 1 day $(\mathrm{SD}=3)$ per cycle (median $=0$ days). ${ }^{65}$ Parous women fared better over time compared to nulliparous women. ${ }^{66}$

Randomized controlled trials have demonstrated that all NSAIDs reduce heavy or prolonged menstrual bleeding with copper IUDs ${ }^{67}$ Antifibrinolytic agents may also reduce blood loss. ${ }^{68}$ Treatment is important not only to reduce distress and increase continuation rates but also to prevent iron deficiency in users. ${ }^{69}$

\section{Expulsion}

In the early clinical trials, expulsions were seen in $5.7 \%$ of women. Lower estimates were seen in more modern studies, where "partial" expulsion was only diagnosed if the device protruded into the cervical canal or when the woman was symptomatic and her IUD was in the lower uterine segment. Early studies reported that nulliparous women had greater expulsion rates than parous women, but more recent studies have shown no association between uterine size and expulsion of the copper IUDs. ${ }^{70}$

\section{Magnetic resonance imaging}

No safety concerns have been found for the use of magnetic resonance imaging (MRI) in users of the CuT-380A IUD as long as the MRI system uses no more than $3.0 \mathrm{~T}$ and the examination requires no longer than 15 minutes of exposure. ${ }^{65}$

\section{Noncontraceptive benefits}

\section{Emergency contraception}

The CuT-380A IUD is the most effective form of EC with a failure rate of $0 \%-0.13 \% .^{71-73}$ Contrary to its usual role as a contraceptive, when a CuT-380A IUD is placed within 120 hours of unprotected intercourse, its placement can function as an interceptive, blocking implantation. ${ }^{74}$ Because manipulating the endometrial cavity after implantation can disrupt a pregnancy; great care must be taken to rule out pregnancy before any IUD is placed.

\section{Cost-effectiveness}

Assuming US Medicare costs for 2014 and typical discontinuation rates, the CuT-380A IUD was found to be the least expensive IUD with a cost of $\$ 304$ per woman, per year. ${ }^{75}$ The minimum period of use for the top-tier contraceptives (IUDs and implants) to achieve cost neutrality compared to pills, patches, and rings was 2.1 years. $^{76}$

\section{Possible new copper IUD options}

Much interest has been focused on two different lines of development for new copper IUDs: 1) controlling the initial bleeding and pain attributable to the "burst effect" of high levels of copper ions released shortly after placement, and 2) redesigning the shape of the IUD to reduce uterine cramping. To achieve the first goal, some investigators have created new copper materials (cross-linked composite-like polyvinyl alcohol containing copper ions or new silicone rubber, nanocopper composite) or have coated the IUD with films or NSAIDs. ${ }^{77-80}$ To achieve the second goal, the plastic frame of the IUD has been removed entirely in GyneFix-Viz ${ }^{\circledR} .{ }^{81,82}$ Other investigators created an intrauterine ball with pure copper spheres threaded over the wires. ${ }^{83}$ Another new IUD replaces the plastic $\mathrm{T}$ frame with a spring-shaped nitinol frame and utilizes low doses of copper strategically placed at the internal os and the tubal ostia $\left(\right.$ VeraCept $\left.^{\circledR}\right)$.

\section{LNG-releasing IUSs}

There are three branded LNG-releasing IUSs currently available in the US. There are two similarly size IUSs with $52 \mathrm{mg}$ LNG and one is smaller with $13.5 \mathrm{mg} \mathrm{LNG}$. The release rates of LNG were measured at different times following the placement, which initially lead to some confusion in naming conventions. For the existing LNG-IUSs and future devices, the convention adopted is that the name will reflect the mean amount of LNG released over a 24 suggested that for women who are above the-hour period during the first year of use.

\section{LNG-releasing IUSs (20 $\mu g / 24$ hours) (Mirena ${ }^{\circledR}$, Liletta/Levosert $\left.{ }^{\circledR}\right)$.}

Description: Each of these IUSs is composed of a T-shaped polyethylene radiopaque frame measuring $32 \mathrm{~mm} \times 32 \mathrm{~mm}$ (Table 2). Encircling the stem is a hormone cylinder composed of a mixture of $52 \mathrm{mg} \mathrm{LNG}$ and silicone (polydimethylsiloxane). Controlling the rate of release of LNG from this reservoir is a semiopaque silicone (polydimethylsiloxane) membrane. A monofilament polyethylene thread is attached to a hook at the end of the vertical stem creating two tailstrings that are useful to reassure the woman of the IUD's continued presence and to facilitate removal. LNG is released during the first year at a rate of $20 \mu \mathrm{g} / \mathrm{d}$. After early equilibration, plasma levels average $150-200 \mathrm{pg} / \mathrm{mL}$. The average levels over the first 3 years were $218 \mathrm{ng} / \mathrm{L} .{ }^{84}$

Indications: The first LNG-IUS 20 that was widely adopted (Mirena) is approved by health authorities in more than 140 countries, for 5 years, for contraception. It is approved in more than 120 countries (including the US) for the treatment of heavy or prolonged menstrual bleeding and in more than 100 (non-US) countries to serve as a source of progestin for postmenopausal estrogen therapy in 
women with an intact uterus. Extended use of the original LNG-IUS for up to 7 years has been suggested for women who are at least 25 years of age at the time of placement. ${ }^{50}$ Currently, the newer version (Liletta/Levosert; Allergan, Inc., Irvine, CA, USA) has only been tested for a limited number of years, so approval is for only 3 years. However, clinical trials are continuing; if the efficacy is maintained, the approval will undoubtedly be expanded in duration. Because the IUD portion of these two products is virtually identical, it is expected that ultimately the clinical impacts will both be the same. However, in the US, Liletta ${ }^{\circledR}$ is approved for contraception only, but in Europe, Levosert ${ }^{\circledR}$ (Uteron Pharma, Liege, Belgium) is also approved for the treatment of heavy menstrual bleeding.

There are two significant differences between these two higher-dose LNG-releasing IUDs: the systems used to place the IUD into the uterine cavity and the price of the IUDs. Both of the LNG-IUSs now use single handed techniques for device placement. The loading and release of the original IUS is simpler and more straightforward than the technique used to place the newer version. The other difference is cost. The Liletta/Levosert was developed by a foundation (Medicines360) to make this top-tier option available to women in low resource areas and to provide it to other women who cannot afford the initial upfront costs. How long the price difference will persist will depend on pricing decisions made by both manufacturers. Another minor difference is that the colors of the tailstring are different (Table 2).

Mechanisms of action: The primary mechanism of action for all progestin IUSs is always local. The most important mechanism is thickening of the cervical mucus to blocking the entry of sperm into the upper genital tracts; ovulation is suppressed in only $\sim 50 \%$ of cycles in the first year of use and in significantly fewer cycles in later years. ${ }^{85}$ Studies show that sperm can penetrate through the cervix mucus by only 2-3 $\mathrm{mm}$ in LNG-IUS users at the time of ovulation $^{86,87}$ and that this impact persists throughout the life of the IUD. Progestin also slows tubal motility, which might explain the increased risk of an ectopic implantation when pregnancy occurs with LNG-IUS use. LNG induces profound endometrial changes, which clearly explains the bleeding abnormalities seen over time with the use of the LNG-IUS. Some have suggested that the progestin-induced endometrial changes might impede implantation, but there is no direct evidence that this occurs. Earlier studies showed that no retrievable blastocysts reach the endometrial cavities of inert IUD users. ${ }^{48,55,58}$

\section{Original LNG-IUS $20 \mu \mathrm{g} / 24$ hours (Mirena)}

Efficacy: In the original clinical trials for Mirena, prevailing practices limited the types of candidates who were included in the study; only women who were parous, who were at low risk for sexually transmitted infections, and who had no history of ectopic pregnancy or PID were studied. In that population, first-year failure rates were $0.14 \%$ and by the end of 5 years, cumulative pregnancy rates were $0.71 \% .^{88}$ More recent analysis has shown that this IUS provides the highest pregnancy protection of all IUDs with a 5-year failure rate of $0.5 \%{ }^{64,66}$

It has been suggested that for women who are above the age of 25 years at the time they initiate the use of the LNG-IUS 20 , the effective life of the device may be extended to 6 years. ${ }^{50}$ An ongoing study involving subjects from the CHOICE study has reported only one pregnancy during the sixth year of use, but the study population had limited numbers. ${ }^{\text {? }}$

\section{Noncontraceptive uses of LNG-IUS 20 (Mirena)}

This LNG-IUS 20 has a wide variety of noncontraceptive health benefits. ${ }^{89,90}$ In one study, $94.6 \%$ of women using the LNG-IUS 20 claimed that they had found noncontraceptive benefits by 12 months and that the use of the LNG-IUS increased their quality of life. ${ }^{85}$ Some of these benefits are highlighted in the following sections.

\section{Treatment for heavy menstrual bleeding}

It is generally recognized that the LNG-IUS-20 is the most effective medical therapy for heavy menstrual bleeding. ${ }^{91,92}$ In the original clinical trial in the US, therapeutic success was defined as decreasing blood loss by at least 50\% and normalizing loss at or below $80 \mathrm{~mL} /$ cycle; $85 \%$ of LNG-IUS users achieved both of those objectives. ${ }^{93}$ Since that study, extensive work has been performed comparing LNG-IUS effectiveness to a wide range of other treatments for heavy menstrual bleeding due to uterine pathology, systemic diseases, exogenous medications, and idiopathic diseases. ${ }^{94}$ LNG-IUS 20 treatment resulted in the fewest hysterectomies and most quality-adjusted life-years, and it was less costly. ${ }^{95}$ In another Cochrane Database Systematic Review, hysterectomy was found to reduce menstrual bleeding better than the LNG-IUS 20 at 1 year, but there was no evidence of a difference in patient satisfaction rates between surgery and LNG-IUS. ${ }^{96}$ In that analysis, adverse events, such as bleeding and spotting, were more likely to occur with LNG-IUS, but surgery was more likely to cause serious complications. The study concluded that the LNG-IUS device provides a 
better alternative to surgery in most cases ${ }^{97}$ Compared to thermal balloon endometrial ablation, a meta-analysis of randomized clinical trials studying the clinical efficacy, safety, cost-effectiveness, and acceptance of ablation vs LNG-IUS concluded that the LNG-IUS is of greater benefit as a long-term treatment therapy. ${ }^{98} \mathrm{~A}$ more recent 5 -year comparative trial (ECLIPSE), which compared LNG-IUS with usual medical therapies, found that at 2 years women's assessments of their bleeding was better with the LNG-IUS, but at 5 years, no difference was detected. ${ }^{99}$ As a result of its impact on having heavy menstrual bleeding, this LNG-IUS is also helpful in treating women with menstrually related iron deficiency anemia. ${ }^{100}$

\section{Treatment of dysmenorrhea}

In women with modest or severe dysmenorrhea due to adenomyosis, dysmenorrhea scores were significantly reduced after 6 months and 12 months of LNG-IUS 20 use. ${ }^{101}$ Severe dysmenorrhea from uterine myoma, endometriosis, or adenomyosis was treated successfully with this LNG-IUS. ${ }^{102-104}$ This IUS also is helpful in reducing the rate of recurrence of endometriosis following initial therapy. ${ }^{105-107}$

\section{Provision of endometrial protection}

The LNG-IUS 20 has been demonstrated to provide endometrial protection from unopposed estrogen administered to control postmenopausal vasomotor symptoms and from tamoxifen. ${ }^{108-110}$ In more than 100 countries, the labeling for this IUS officially endorses its use as a source of progestin for postmenopausal women using estrogen, because it has been shown to prevent atypical endometrial hyperplasia and endometrial cancer.

\section{Treatment of endometrial hyperplasia}

Several studies have verified that $>90 \%$ of endometrial hyperplasia with and without atypia cleared with treatment with the original LNG-IUS 20. ${ }^{11-113}$ Additional case reports have documented that the LNG-IUS with or without oral progestin successfully reversed early-stage endometrial carcinoma. ${ }^{114,115}$ However, continued therapy is needed after initial clearance, because relapse rates of $>40 \%$ were observed within 24 months of cessation of therapy. ${ }^{116}$

\section{Emergency contraception (EC)}

Although there is no evidence to support the use of the LNG-IUS for EC, the practice of combining the LNG-IUS and oral LNGEC has been shown to be more popular in one study than the use of the copper IUD by a 2:1 ratio. ${ }^{117}$ No pregnancies occurred in any of the 188 women enrolled in this pilot project. ${ }^{118}$

\section{Newer branded LNG-IUS 20 mg/24 h (Liletta/Levosert)}

Medicines360, a nonprofit women's health pharmaceutical company founded to expand access to quality women's health products, has been conducting the clinical trials of a new IUS with $52 \mu \mathrm{g}$ of LNG (Table 2). These trials to date have provided the data that formed the basis for the initial 3-year approval by the FDA/European Medicines Agency of Liletta/ Levosert for that time period. Those trials are ongoing and are planned to continue until 7-year data are obtained. ${ }^{118} \mathrm{New}$ studies demonstrated that increase rates of levonorgestrel at 5 years are therapeutic. ${ }^{119}$ There are minor structural differences between the two LNG-IUS 20 devices. The arms have slightly different shapes and the vertical arm of the newer version is thinner ( $1.2 \mathrm{~mm}$ vs $1.5 \mathrm{~mm}$ in diameter). The thread loop is also smaller and colored blue. The introduction apparatus for the newer device is a two-handed tube similar to that used with the Nova-T IUD.

For the clinical trials of this more recently approved LNGIUS, women who met the US MEC criteria were included. In particular, more than half of the women in these clinical trials were nulliparous. ${ }^{118}$ Placement was successful in 98\% of candidates, but $0.7 \%$ of those did not have placement completed because of problems with uterine sounding and other problems. ${ }^{118}$ In this study, same-day/quick start placement was encouraged, consistent with modern practice recommendations.

\section{Efficacy}

The Pearl Indices for each of the first 3 years were $0.15(95 \%$ CI: $0.02-0.55), 0.2$ (95\% CI: $0.10-0.57)$, and 0.22 (95\% CI: $0.08-0.49)$ per 100 women-cycles, respectively. ${ }^{118}$ The life table analysis yielded a pregnancy rate of 0.55 during 3 years. Ectopic pregnancies accounted for two-thirds of the pregnancies for a rate of $0.12 / 100$ women-years in a population with no prior history of ectopic pregnancies. ${ }^{118}$

\section{Bleeding patterns}

The mean numbers of days of bleeding and spotting declined rapidly from 14.7 days in the first 90 -day cycle to 3.9 days in the 13th day cycle. ${ }^{118}$ At every point in time in the majority of those days, women experienced only spotting. Amenorrhea rates progressively increased with time reaching 19\%, 26\%, and $38 \%$ by the end of each year in the clinical trial; these numbers are very reminiscent of the amenorrhea rates seen with the original LNG-IUS $20 .{ }^{118}$ Despite the fact that amenorrhea is prevalent with long-term use of the LNG-IUS 20, there is no concern for bone loss because the amenorrhea results from local progestin effects on the endometrium, not from ovarian suppression. Studies of bone mineral density (BMD) 
at the midshaft of the ulna showed no differences between nonhormonal IUD users and women who used LNG-IUS 20. ${ }^{120}$

\section{Expulsion rates}

Expulsion occurred in $3.5 \%$ of women $3.6 \%$ of women with successful placement). ${ }^{118}$ Nulliparous women had lower expulsion rates $(2.0 \%)$ than parous women $(5.6 \%)$. Most expulsions $(80.6 \%)$ occurred in the first year of use. Complete expulsions comprised only $43.5 \%$ of all expulsions. ${ }^{118}$ In a parallel European study of the device for heavy menstrual bleeding, the expulsion rate was $4.2 \%$; again the rates were higher among parous women than nulliparous women. ${ }^{121}$

\section{Discontinuation rates}

In total, $38.5 \%$ of women in the US clinical had early removal of the this IUD. Discontinuation due to adverse events occurred in $12.3 \%$ of users over the first 3 years of the study. ${ }^{118}$ The most common adverse events leading to discontinuation were expulsion (3.5\%), bleeding complaints $(1.5 \%)$, acne $(1.3 \%)$, and mood swings $(1.3 \%) .{ }^{118}$

\section{Side effects}

In the same US clinical trial, uterine perforation was reported in $0.17 \%$ of cases. ${ }^{118}$ Two of the perforations required surgical removal. It must be noted that breastfeeding women were excluded from the trial. ${ }^{118}$ The rates of ovarian cysts reported in this study reflect only symptomatic cysts; they were reported in $3.4 \%$ of women, but only $0.3 \%$ discontinued the use of the IUS because of an ovarian cyst. Most ovarian cysts disappeared within 2-3 months of discovery. ${ }^{118}$ Pelvic infection was reported in $0.6 \% ; 70 \%$ were diagnosed as PID; $30 \%$ as endometritis. ${ }^{118}$ One-third of cases were diagnosed within 1 week of placement. Seventy percent were successfully treated without removal of the IUS. Interestingly, 1.3\% of subjects were diagnosed with chlamydia at baseline, but none of them developed pelvic infections. ${ }^{118}$

\section{Return to fertility}

Of the 68 women followed up for return to fertility, $86.8 \%$ conceived spontaneously within 12 months. ${ }^{118}$

\section{Noncontraceptive benefits}

\section{Heavy menstrual bleeding}

In Europe, the regulatory authorities granted this IUS labeling indication as treatment for heavy menstrual bleeding. This was based on a 1-year randomized, comparative trial of 280 women with $\mathrm{MBL}$ of $\geq 80 \mathrm{~mL} /$ cycle evaluated by validated modified version of the Wyatt Pictogram. ${ }^{121}$ Women were randomized $(1: 1)$ to Mirena vs Levosert. Both IUDs decreased the MBL and increased hemoglobin and ferritin levels equally. Similar bleeding patterns were observed in each arm; expulsion rates were identical in the intent-to-treat population. Menstrual blood loss decreased by $142.3 \mathrm{~mL}$ in the Levosert arm and $146.4 \mathrm{~mL}$ in the Mirena arm. ${ }^{121}$ Declines were slightly greater in the per-protocol populations (150.9 mL and $151.2 \mathrm{~mL}$, respectively). Endometrial thickness diminished by $7.8 \mathrm{~mm}$ and $7.4 \mathrm{~mm} .{ }^{121}$

\section{LNG-IUS 8 (Skyla/Jaydess $\left.{ }^{\circledR}\right)$}

The LNG-IUS 8 (Bayer Healthcare Pharmaceuticals) has the same basic structure as higher-dose LNG-IUSs, but is smaller in both vertical and horizontal dimensions. The arms measure $28 \mathrm{~mm}$, and the stem is $30 \mathrm{~mm}$ long (Table 2). The T-shaped frame is made of polyethylene. The reservoir has only $13.5 \mathrm{mg}$ LNG wrapped around the stem. The monofilament tailstrings are identical to Mirena. ${ }^{122}$ The LNG-IUS 8 is introduced into the uterine cavity in a tubing with a smaller outer diameter of $3.8 \mathrm{~mm}$. To distinguish this lower-dose IUD on imaging from its higher-dose versions, a ring of $99.95 \%$ pure silver was placed at the top of the vertical stem close to the horizontal arms. ${ }^{122}$ Even with the small ring, it is safe to perform MRI as long as the machine is rated no higher than $3 \mathrm{~T}$, and the examination does not exceed 15 minutes.

Marketed in the US as Skyla and worldwide as Jaydess, this lower-dose, 3-year IUD with $13.5 \mathrm{mg}$ LNG releases an average of $8 \mu \mathrm{g} / \mathrm{d}$ over the first year. ${ }^{123}$ In the comparative Phase II trials, the serum LNG levels over 3 years averaged $74.3 \mathrm{ng} / \mathrm{L}$ for the LNG-IUS 8 vs $218 \mathrm{ng} / \mathrm{L}$ for the LNG-IUS 20. Similar progestogenic effects were observed on cervical mucus for both doses. Ovulation occurred in the majority of cycles with each of the devices, but was higher in the low-dose version. ${ }^{123}$

In the Phase III clinical trials, two low-dose versions of the LNG-IUS were studied, including the LNG-IUS 8. Overall 1,432 women were randomized to the LNG-IUS 8 and followed up for up to 3 years; $38.8 \%$ of them were nulliparous and another $12 \%$ had only delivered by cesarean section; $39 \%$ were aged $\leq 25$ years. ${ }^{122}$ Efficacy and satisfaction did not vary by age, parity, or body mass index. ${ }^{122}$ In a more recent Phase III single-arm study of LNG-IUS 8, 304 adolescents aged 12-17 years inclusive were followed up for up to 1 year for treatment-emergent adverse effects, satisfaction, discontinuation rate, and Pearl Index. ${ }^{124}$

The narrower placement tube was associated in the pivotal trial with a "very difficult" placement in $1 \%$ of cases as rated by the clinician; $65 \%$ of subjects in the pivotal trial rated the pain they experienced with placement as "none" or "mild"; $8 \%$ reported that the pain was "severe". ${ }^{122}$ Placement was 
successful in $99.5 \% ; 96 \%$ were performed with only one attempt. ${ }^{122}$ In the teen trial, the numbers were similar, with $54.8 \%$ of women rating pain as "none" or "mild", but $10.9 \%$ rated it as "severe". Placement was achieved in all but one patient. ${ }^{124}$ No perforations were reported in either trial.

\section{Efficacy}

In the Phase III pivotal clinical studies for the LNG-IUS 8, the Pearl Indices by year were 0.41 (95\% CI: 0.13-0.96), 0.30 (95\% CI: 0.06-0.86), and 0.24 (95\% CI: 0.03-0.88). ${ }^{122}$ The cumulative 3-year Pearl Inde was 0.33 (95\% CI: 0.16-0.60). The Kaplan-Meier estimates for the failure rates over 3 years were $0.9 \%{ }^{122}$ The ectopic pregnancy rate was $0.10 / 100$ women-years (95\% CI: $0.02-0.29) .{ }^{122}$ In the teen study, no pregnancies were reported in the 12 -month period. ${ }^{124}$

\section{Discontinuation rates}

In the pivotal trial, $57 \%$ of subjects completed the full 3 -year trial. ${ }^{122}$ Overall, $21.0 \%$ discontinued early due to an adverse event and $4.7 \%$ requested early removal due to bleeding complaints. In the teen study, $16.8 \%$ prematurely discontinued before 12 months. ${ }^{124}$ Bleeding was a rare cause of discontinuation $(<1 \%)$, but pelvic pain $(3.6 \%)$ and dysmenorrhea $(1.6 \%)$ were more frequent reasons given for discontinuation. ${ }^{122}$

Bleeding patterns with the LNG-IUS 8 are substantially different from those observed in general with the LNG-IUS $20 .{ }^{125}$ With both IUSs, substantial unscheduled spotting and bleeding occur in the first 3-4 months of use; however, the rates diminish rapidly over time and most events represent spotting rather than bleeding. Amenorrhea rates were significantly lower among LNG-IUS 8 users; by the end of the 3 years, only $12 \%$ of women experienced amenorrhea for the last 90 -day period. ${ }^{122}$

\section{Side effects}

In the 3-year pivotal trial, the rate of partial or complete expulsion was $4.56 \%$, but that rate included cases early in the trial in which non-fundal placements visualized on routine ultrasound study were counted as partial expulsions. ${ }^{122}$ In the 1 -year adolescent study, the expulsion rate was 3.3\% (12.2\% among nulliparous women and $4.2 \%$ in parous women). ${ }^{124}$

Six cases of pelvic infection were diagnosed in the pivotal trial, comprising $0.14 \%$ of the subjects. ${ }^{122}$ In the adolescent trial, the rate of PID was lower in nulliparous users $(0.17 \%)$ compared to parous women $(0.6 \%) .{ }^{124}$ Routine pelvic ultrasounds were performed throughout the clinical trial, during which ovarian cysts were observed in $7.7 \%$ of cases. ${ }^{122}$ In a subgroup, BMD was studied; no reduction in BMD was observed. ${ }^{122}$

\section{Potential new hormonal IUDs}

A middle-dose LNG-IUS containing $19.5 \mathrm{mg}$ LNG has been tested; on average, it releases $12 \mu \mathrm{g} \mathrm{LNG} / \mathrm{d}$ during the first year of use. ${ }^{123}$ This IUD was initially included in the pivotal trial of the currently available LNG-IUS $8 .{ }^{122}$ At the end of that 3-year trial, it was recognized that there was still a significant amount of LNG in the reservoir to permit a longer effective life. Women who had randomized to the $19.5 \mathrm{mg}$ LNG-IUS were then invited to enroll in a 2-year extension trial. That extended trial is now complete and the data have been submitted to the regulatory authorities. It is quite likely that this low-dose 5-year IUD will become available in the near future. Other hormonal compounds, including etonogestrel, nestorone, and even ulipristal acetate, could be provided in IUD frames, but none of these have yet progressed into large-scale clinical trials.

\section{Other new IUD developments}

Several new devices have been tested to improve the safety of IUD placement or to reduce the discomfort associated with the procedure. For example, one device is designed to replace the tenacculum with a suction device that can be placed over the cervix to capture and stabilize it while allowing the IUD to be placed through a channel running down the middle of the device. Another device (a "smart IUD launcher") could detect a specific distance to the uterine wall to prevent uterine perforation with the release of the IUD. ${ }^{126}$

\section{Residual patient concerns}

Even if all of these devices do become available, recent experience shows that women may not enthusiastically adopt them because of issues that may or may not have anything to do with the features of the individual IUDs. The potential changes in uterine bleeding may discourage some women, but studies have showed that more fundamental concerns influence women's decisions. One study of urban adolescents who were aware of IUDs, but had never used one, revealed considerable fear about pain with the IUD - not only with placement but also with the ongoing pain associated with the use of the device. ${ }^{127}$ Some of the types of pain they feared (pain with urination or intercourse) revealed a profound lack of knowledge of anatomy. Fear of expulsion and fear of having a foreign body inside them were also common. There was also fear of undefined physical harm that could result from IUD use, although fear of infection was not common. 
In general, these young women generally believed that the IUD could be "for someone else" or may be best used as a "second-line method" to be considered only after another method had failed. ${ }^{127}$

Other issues could be impeding adoption of top-tier methods. IUDs would seem to be best suited for women who appreciate the high efficacy and convenience of their method. However, this statement implies that women plan their pregnancies and chose methods that match those reproductive life plans because they understand that different contraceptives offer different levels of pregnancy protection. Despite significant public health campaigns to help women develop personal reproductive life plans, ${ }^{128}$ recent work has shown that many at-risk women have not developed such plans to guide them in making contraceptive choices. ${ }^{129,130}$

Focus group work by Borrero et al, appropriately titled "It Just Happens", revealed that for many sexually active young women, "planning for pregnancy" is not understood. ${ }^{131}$ For some, pregnancy planning is even taboo until the woman meets minimal social and financial standards - standards that may not be possible for many indigent women. ${ }^{131}$ However, if pregnancy "happens", it is likely to be accepted. In this setting, methods with low accidental pregnancy rates may be less likely to be embraced.

Several studies have shown that even when women are deliberately trying to avoid pregnancy, there is a great mismatch between the efficacy of methods used by women and their desire to prevent pregnancy. ${ }^{129,130}$ Against this background, it may be understood that women are not impressed with the low failure rates of IUDs.

In a recent study of adolescents, the National Campaign for Prevention of Unintended and Adolescent Pregnancy reported several findings that may help explain relatively low IUD utilization rates and also that bear directly on the ability of professionals to effectively counsel young women about contraception. ${ }^{132}$ They found that most women are not aware of their options; women need to be counseled in order of efficacy (implants and IUDs first). Second, they found that high effectiveness is not a distinguishing feature to young women because they expected it of all methods. "Long acting" is a term that does not resonate well with young women; "low maintenance" is much more appealing. Acknowledging that contraception is dynamic helps women accept a method. The most ominous finding of the study is that, although these women often confuse IUDs and implants, they are bundling them together as "invasive methods". In part, this may have developed in response to the vocabulary clinicians use - words such as "insert" an
IUD instead of "place" an IUD. Women do not know what to expect during "insertion" or with the use of the method, and such knowledge gaps lead to underutilization. This work strongly recommend that clinicians share experiences that other women have had with each method - both the good and the bad - using everyday language. Finally, for younger women, it is important to reassure them that IUDs are safe for them and their future fertility. ${ }^{132}$

\section{Conclusion}

A summary of features outlined earlier that may be helpful to consider in selecting among available IUDs in the US is as follows:

- The copper IUD is particularly attractive to women who do not have heavy menstrual bleeding and wish to continue to have monthly menses, women who wish to avoid hormones, and women who have medical conditions that preclude the use of hormones. The copper IUD is the only IUD that provides both $\mathrm{EC}$ and immediate contraceptive protection.

- Choices among the various LNG-IUSs are more complicated. In general, an LNG-IUS is very appropriate for women who seek to reduce menstrual bleeding and will tolerate at least short-term unscheduled spotting and bleeding and variable prevalence of amenorrhea.

- The LNG-IUS 20 (Mirena) is approved in the US for 5 years of use for contraception and for the treatment of heavy menstrual bleeding. In more than 100 countries, this IUD is also approved as a source of progestogen to prevent endometrial proliferation with the use of postmenopausal estrogen therapy. The applicator used to place this IUS utilizes a straightforward single-handed placement procedure. The cost of this IUD generally tends to be higher than the newer version.

- The LNG-IUS 20(Liletta/Levosert) is very comparable to the Mirena, but it is currently approved for only 3 years. However, clinical trials are continuing to study its potential for use for up to 7 years. In the European Union, but not in the US, this IUS is also approved for the treatment of heavy menstrual bleeding. Placement of this IUS involves a slightly more complicated one-hand procedure. The main advantage of this LNG-IUS 20 is its price. It was specifically developed to try to provide an affordable top-tier method to women, especially those in developing countries and those elsewhere with few resources.

- LNG-IUS 8 is a 3 -year, smaller device that releases lower levels of hormone and is placed using a narrower diameter tubing. The lower hormone levels result in lower 
prevalence of amenorrhea, which may appeal to women who do not want increasing blood loss (as with copper IUD), but do not want amenorrhea (LNG-IUS 20).

All IUDs can be offered to women who are nulliparous (vs parous), adolescent (vs older age), and in different relationships (completely monogamous vs low-risk nonmonogamous). Placement can occur any time in a woman's cycle when the clinician is confident that the woman is not pregnant, including postpartum and postabortal placements.

\section{Disclosure}

Anita L Nelson declares that she has received grant funding from Teva Pharmaceutical Industries Ltd., Bayer Healthcare Pharmaceuticals, and ContraMed. She also has received honoraria for serving on advisory boards for Bayer Healthcare Pharmaceuticals and ContraMed and for speaker's bureau activity with Bayer Healthcare Pharmaceuticals, Allergan, Inc., Irvine, CA, USA, and Pharmanest. Natasha Massoudi reports no conflicts of interest in this work.

\section{References}

1. United Nations. Department of Economic and Social Affair, Population Division. World Contraceptive Use 2011. Available from: 111.un.org/ esa/population/publications/contraceptive/2011/contraceptive2011.htm.

2. Finer LB, Zolna MR. Declines in unintended pregnancy in the United States, 2008-2011. N Engl J Med. 2016;374(9):843-852.

3. Harper CC, Rocca CH, Thompson KM, et al. Reductions in pregnancy rates in the USA with long-acting reversible contraception: a cluster randomised trial. Lancet. 2015;386(9993):562-568.

4. Mumford SD, Kessel E. Was the Dalkon Shield a safe and effective intrauterine device? The conflict between case-control and clinical trial study findings. Fertil Steril. 1992;57(6):1151-1176.

5. Sivin I. Another look at the Dalkon Shield: meta-analysis underscores its problems. Contraception. 1993;48(1):1-12.

6. Daling JR, Weiss NS, Metch BJ, et al. Primary tubal infertility in relation to the use of an intrauterine device. NEngl J Med. 1985;312(15): 937-941

7. Diedrich JT, Madden T, Zhao Q, Peipert JF. Long-term utilization and continuation of intrauterine devices. Am J Obstet Gynecol. 2015;213(6):822.e1-e6.

8. Birgisson NE, Zhao Q, Secura GM, Madden T, Peipert JF. Preventing unintended pregnancy: the contraceptive CHOICE project in review. $J$ Womens Health (Larchmt). 2015;24(5):349-353.

9. Ricketts S, Klingler G, Schwalberg R. Game change in Colorado: widespread use of long-acting reversible contraceptives and rapid decline in births among young, low-income women. Perspect Sex Reprod Health. 2014;46(3):125-132.

10. CDC [webpage on the Internet]. CDC United States Medical Eligibility Criteria (US MEC) for Contraceptive Use. 2010. Available from: http://www.cdc.gov/reproductivehealth/unintendedpregnancy/usmec. htm. Accessed July 12, 2016.

11. World Health Organization (WHO) [webpage on the Internet]. Medical Eligibility Criteria for Contraceptive Use. Fifth ed. 2015. Available from: http://apps.who.int/iris/bitstream/10665/172915/1/ WHO_RHR_15.07_eng.pdf. Accessed July 12, 2016.

12. CDC United States Selected Practice Recommendations (US SPR) for Contraceptive Use. 2016. 2016;65(4):1-65. Available from: 111.cdc. gov/reproductivehealth/contraception/usspr.htm.
13. World Health Organization (WHO) [webpage on the Internet]. Selected Practice Recommendations for Contraceptive Use. 2014. Available from: http://apps.who.int/iris/bitstream/10665/43097/1/9241562846. pdf. Accessed July 12, 2016.

14. AAP [webpage on the Internet]. American Academy of Pediatrics (AAP) Contraception for Adolescents. Available from: http://pediatrics. aappublications.org/content/134/4/e1257. Accessed July 12, 2016.

15. Committee on Adolescent Health Care Long-Acting Reversible Contraception Working Group, The American College of Obstetricians and Gynecologists. Committee opinion no. 539: adolescents and long-acting reversible contraception: implants and intrauterine devices. Obstet Gynecol. 2012;120(4):983-988.

16. Law A, Wen L, Lin J, Tangirala M, Schwartz JS, Zampaglione E. Are women benefiting from the Affordable Care Act? A real-world evaluation of the impact of the Affordable Care Act on out-of-pocket costs for contraceptives. Contraception. 2016;93(5):392-397.

17. Bednarek PH, Creinin MD, Reeves MF, et al; Post-Aspiration IUD Randomization (PAIR) Study Trial Group. Immediate versus delayed IUD insertion after uterine aspiration. N Engl J Med. 2011;364(23): 2208-2217.

18. Rose SB, Lawton BA. Impact of long-acting reversible contraception on return for repeat abortion. Am J Obstet Gynecol. 2012;206(1):37. e1-e6.

19. Lopez LM, Bernholc A, Hubacher D, Stuart G, Van Vliet HA. Immediate postpartum insertion of intrauterine device for contraception. Cochrane Database Syst Rev. 2015;6:CD003036.

20. Cohen R, Sheeder J, Arango N, Teal SB, Tocce K. Twelve-month contraceptive continuation and repeat pregnancy among young mothers choosing postdelivery contraceptive implants or postplacental intrauterine devices. Contraception. 2016;93(2):178-183.

21. Chen BA, Reeves MF, Creinin MD, Schwarz EB. Postplacental or delayed levonorgestrel intrauterine device insertion and breast-feeding duration. Contraception. 2011;84(5):499-504.

22. Royer PA, Turok DK, Sanders JN, Saltzman HM. Choice of emergency contraceptive making regarding and decision subsequent unintended pregnancy. J Womens Health (Larchmt). 2016. Epub 2016 Mar 31.

23. Abu Hashim H, Ghayaty E, El Rakhawy M. Levonorgestrel-releasing intrauterine system vs oral progestins for non-atypical endometrial hyperplasia: a systematic review and metaanalysis of randomized trials. Am J Obstet Gynecol. 2015;213(4):469-478.

24. Cholakian D, Hacker K, Fader AN, Gehrig PA, Tanner EJ 3rd. Effect of oral versus intrauterine progestins on weight in women undergoing fertility preserving therapy for complex atypical hyperplasia or endometrial cancer. Gynecol Oncol. 2016;140(2):234-238.

25. Depypere H, Inki P. The levonorgestrel-releasing intrauterine system for endometrial protection during estrogen replacement therapy: a clinical review. Climacteric. 2015;18(4):470-482.

26. Kavanaugh ML, Jerman J, Finer LB. Changes in use of long-acting reversible contraceptive methods among U.S. women, 2009-2012. Obstet Gynecol. 2015;126(5):917-927.

27. Papic M, Wang N, Parisi SM, Baldauf E, Updike G, Schwarz EB. Same-day intrauterine device placement is rarely complicated by pelvic infection. Womens Health Issues. 2015;25(1):22-27.

28. Reeves MF, Zhao Q, Secura GM, Peipert JF. Risk of unintended pregnancy based on intended compared to actual contraceptive use. Am J Obstet Gynecol. 2016;215(1):71.e1-e6.

29. Doty N, MacIsaac L. Effect of an atraumatic vulsellum versus a singletooth tenaculum on pain perception during intrauterine device insertion: a randomized controlled trial. Contraception. 2015;92(6):567-571.

30. Lopez LM, Bernholc A, Zeng Y, et al. Interventions for pain with intrauterine device insertion. Cochrane Database Syst Rev. 2015;7:CD007373.

31. Ngo LL, Ward KK, Mody SK. Ketorolac for pain control with intrauterine device placement: a randomized controlled trial. Obstet Gynecol. 2015;126(1):29-36.

32. Hubacher D, Reyes V, Lillo S, Zepeda A, Chen PL, Croxatto H. Pain from copper intrauterine device insertion: randomized trial of prophylactic ibuprofen. Am J Obstet Gynecol. 2006;195(5):1272-1277. 
33. Bednarek PH, Creinin MD, Reeves MF, Cwiak C, Espey E, Jensen JT. Post-aspiration IUD randomization (PAIR) study trial group. Prophylactic ibuprofen does not improve pain with IUD insertion: a randomized trial. Contraception. 2015;91(3):193-197.

34. Massey SE, Varady JC, Henzl MR. Pain relief with naproxen following insertion of an intrauterine device. J Reprod Med. 1974;13(6):226-231.

35. Karabayirli S, Ayrim AA, Muslu B. Comparison of the analgesic effects of oral tramadol and naproxen sodium on pain relief during IUD insertion. J Minim Invasive Gynecol. 2012;19(5):581-584.

36. McNicholas CP, Madden T, Zhao Q, Secura G, Allsworth JE, Peipert JF. Cervical lidocaine for IUD insertional pain: a randomized controlled trial. Am J Obstet Gynecol. 2012;207(5):384.e1-e6.

37. Allen RH, Raker C, Goyal V. Higher dose cervical $2 \%$ lidocaine gel for IUD insertion: a randomized controlled trial. Contraception. 2013;88(6):730-736.

38. Aksoy H, Aksoy Ü, Ozyurt S, Açmaz G, Babayigit M. Lidocaine $10 \%$ spray to the cervix reduces pain during intrauterine device insertion: a double-blind randomised controlled trial. J Fam Plann Reprod Health Care. 2016;42(2):83-87.

39. Nelson AL, Fong JK. Intrauterine infusion of lidocaine does not reduce pain scores during IUD insertion. Contraception. 2013;88(1):37-40.

40. Tornblom-Paulander S, Tingåker BK, Werner A, et al. Novel topical formulation of lidocaine provides significant pain relief for intrauterine device insertion: pharmacokinetic evaluation and randomized placebocontrolled trial. Fertil Steril. 2015;103(2):422-427.

41. Tavakolian S, Doulabi MA, Baghban AA, Mortazavi A, Ghorbani M. Lidocaine-prilocaine cream as analgesia for IUD insertion: a prospective, randomized, controlled, triplebBlinded study. Glob J Health Sci. 2015;7(4):399-404.

42. Dijkhuizen K, Dekkers OM, Holleboom CA, et al. Vaginal misoprostol prior to insertion of an intrauterine device: an RCT. Hum Reprod. 2011;26(2):323-329.

43. Krediet CT, van Dijk N, Linzer M, van Lieshout JJ, Wieling W. Management of vasovagal syncope: controlling or aborting faints by leg crossing and muscle tensing. Circulation. 2002;106(13):1684-1689.

44. Groothuis JT, van Dijk N, Ter Woerds W, Wieling W, Hopman MT. Leg crossing with muscle tensing, a physical counter-maneuver to prevent syncope, enhances leg blood flow. Clin Sci (Lond). 2007; 112(3):193-201.

45. Ortho Pharmaceutical Corporation [webpage on the Internet]. ParaGard Prescribing Information. Raritan, NJ: Ortho Pharmaceutical Corporation; 1995. Available from: http://www.accessdata.fda.gov/ drugsatfda_docs/label/2005/018680s060lbl.pdf. Accessed July 12, 2016.

46. Sivin I. Utility and drawbacks of continuous use of a CuT 380A IUD for 20 years. Contraception. 2007;75(6 suppl):S70-S75.

47. Wu JP, Pickle S. Extended use of the intrauterine device: a literature review and recommendations for clinical practice. Contraception. 2014;89(6):495-503.

48. Heinemann K, Reed S, Moehner S, Minh TD. Risk of uterine perforation with levonorgestrel-releasing and copper intrauterine devices in the European Active Surveillance Study on Intrauterine Devices. Contraception. 2015;91(4):274-279.

49. Segal SJ, Alvarez-Sanchez F, Adejuwon CA, Brache de Mejia V, Leon P, Faundes A. Absence of chorionic gonadotropin in sera of women who use intrauterine devices. Fertil Steril. 1985;44(2):214-218.

50. Kho KA, Chamsy DJ. Perforated intraperitoneal intrauterine contraceptive devices: diagnosis, management, and clinical outcomes. J Minim Invasive Gynecol. 2014;21(4):596-601.

51. Stanford JB, Mikolajczyk RT. Mechanisms of action of intrauterine devices: update and estimation of post-fertilization effects. Am J Obstet Gynecol. 2002;187(6):1699-1708.

52. Ortiz ME, Croxatto HB. The mode of action of IUDs. Contraception. 1987;36(1):37-53.

53. Alvarez F, Brache V, Fernandez E, et al. New insights on the mode of action of intrauterine contraceptive devices in women. Fertil Steril. 1988;49(5):768-773.
54. El-Habashi M, El-Sahwi S, Gawish S, Osman M. Effect of Lippes loop on sperm recovery from human fallopian tubes. Contraception. 1980;22(5):549-555.

55. Kesserü E, Camacho-Ortega P. Influence of metals on in vitro sperm migration in the human cervical mucus. Contraception. 1972;6(3):231-240.

56. Rivera R, Yacobson I, Grimes D. The mechanism of action of hormonal contraceptives and intrauterine contraceptive devices. Am J Obstet Gynecol. 1999;181(5 pt 1):1263-1269.

57. Rowe P, Farley T, Peregoudov A, et al; IUD Research Group of the UNDP/UNFPA/WHO/World Bank Special Programme of Research; Development and Research Training in Human Reproduction. Safety and efficacy in parous women of a 52-mg levonorgestrel-medicated intrauterine device: a 7-year randomized comparative study with the TCu380A. Contraception. 2016;93(6):498-506.

58. United Nations Dev. Long-term reversible contraception. Twelve years of experience with the TCu380A and TCu220C. Contraception. 1997;56(6):341-352.

59. Thonneau PF, Almont T. Contraceptive efficacy of intrauterine devices. Am J Obstet Gynecol. 2008;198(3):248-253.

60. Heinemann K, Reed S, Moehner S, Minh TD. Comparative contraceptive effectiveness of levonorgestrel-releasing and copper intrauterine devices: the European Active Surveillance Study for Intrauterine Devices. Contraception. 2015;91(4):280-283.

61. Kaneshiro B, Aeby T. Long-term safety, efficacy, and patient acceptability of the intrauterine Copper T-380A contraceptive device. Int $J$ Womens Health. 2010;2:211-220.

62. Economic and Social Affairs [webpage on the Internet]. Trends in Contraceptive Use Worldwide. 2015. Available from: http://www. un.org/en/development/desa/population/publications/pdf/family/ trendsContraceptiveUse2015Report.pdf. Accessed July 12, 2016.

63. Kakaire O, Byamugisha JK, Tumwesigye NM, Gemzell-Danielsson K. Intrauterine contraception among women living with human immunodeficiency virus: a randomized controlled trial. Obstet Gynecol. 2015;126(5):928-934.

64. Milsom I, Andersson K, Jonasson K, Lindstedt G, Rybo G. The influence of the Gyne-T 380S IUD on menstrual blood loss and iron status. Contraception. 1995;52(3):175-179.

65. Zieman M, Kanal E. Copper T 380A IUD and magnetic resonance imaging. Contraception. 2007;75(2):93-95.

66. Hubacher D, Chen PL, Park S. Side effects from the copper IUD: do they decrease over time? Contraception. 2009;79(5):356-362.

67. Grimes DA, Hubacher D, Lopez LM, Schulz KF. Non-steroidal antiinflammatory drugs for heavy bleeding or pain associated with intrauterine-device use. Cochrane Database Syst Rev. 2006;(4):CD006034.

68. Godfrey EM, Folger SG, Jeng G, Jamieson DJ, Curtis KM. Treatment of bleeding irregularities in women with copper-containing IUDs: a systematic review. Contraception. 2013;87(5):549-566.

69. Effects of contraceptives on hemoglobin and ferritin. Task Force for Epidemiological Research on Reproductive Health, United Nations Development Programme/United Nations Population Fund/World Health Organization/World Bank Special Programme of Research, Development and Research Training in Human Reproduction, World Health Organization, Geneva, Switzerland. Contraception. 1998;58(5):262-273

70. Kaislasuo J, Heikinheimo O, Lähteenmäki P, Suhonen S. Menstrual characteristics and ultrasonographic uterine cavity measurements predict bleeding and pain in nulligravid women using intrauterine contraception. Hum Reprod. 2015;30(7):1580-1588.

71. Bilian X. Chinese experience with intrauterine devices. Contraception. 2007;75(6 suppl):S31-S34.

72. Fasoli M, Parazzini F, Cecchetti G, La Vecchia C. Post-coital contraception: an overview of published studies. Contraception. 1989;39(4):459-468.

73. Wu S, Godfrey EM, Wojdyla D, et al. T380A intrauterine device for emergency contraception: a prospective, multicentre, cohort clinical trial. BJOG. 2010;117(10):1205-1210. 
74. Cheng L, Che Y, Gülmezoglu AM. Interventions for emergency contraception. Cochrane Database Syst Rev. 2012;8:CD001324.

75. Trussell J, Hassan F, Lowin J, Law A, Filonenko A. Achieving costneutrality with long-acting reversible contraceptive methods. Contraception. 2015;91(1):49-56.

76. Chen Y, Luo Y, Jia Z, Jia D, Chen J. Preparation and characterization of silicone rubber/nano-copper nanocomposites for use in intrauterine devices. Biomed Mater Eng. 2014;24(1):1269-1274.

77. Li J, Suo J, Huang X, Ye C, Wu X. Release behavior of copper ion in a novel contraceptive composite. Contraception. 2007;76(3): 233-237.

78. Ramakrishnan R, B B, Aprem AS. Controlled release of copper from an intrauterine device using a biodegradable polymer. Contraception. 2015;92(6):585-588.

79. Jinying L, Ying L, Xuan G, Yanli G, Jianping L. Investigation of the release behavior of cupric ion for three types of $\mathrm{Cu}$-IUDs and indomethacin for medicated u-IUD in simulated uterine fluid. Contraception. 2008;77(4):299-302.

80. Xu XX, Nie FL, Wang YB, et al. Effective inhibition of the early copper ion burst release with ultra-fine grained copper and single crystal copper for intrauterine device application. Acta Biomater. 2012;8(2):886-896.

81. Wildemeersch D, Goldstuck ND, Hasskamp T. Intrauterine systems: a frameless future? Expert Opin Drug Deliv. 2016;13(6):911-918.

82. Wildemeersch D, Pett A, Jandi S, Nolte K. New visualized anchor for framless IUD is helpful for checking correct insertion. J Fam Plann Reprod Health Care. 2014;40(4):310-311.

83. Baram I, Weinstein A, Trussell J. The IUB, a newly invented IUD: a brief report. Contraception. 2014;89(2):139-141.

84. Apter D, Gemzell-Danielsson K, Hauck B, Rosen K, Zurth C. Pharmacokinetics of two low-dose levonorgestrel-releasing intrauterine systems and effects on ovulation rate and cervical function: pooled analyses of phase II and III studies. Fertil Steril. 2014;101(6): 1656-1662.e1-e4.

85. Cristobal I, Lete LI, Viuda Ede L, Perulero N, Arbat A, Canals I. One year quality of life measured with SEC-QoL in levonorgestrel $52 \mathrm{mg}$ IUS users. Contraception. 2016;93(4):367-371.

86. Lewis RA, Taylor D, Natavio MF, Melamed A, Felix J, Mishell D Jr. Effects of the levonorgestrel-releasing intrauterine system on cervical mucus quality and sperm penetrability. Contraception. 2010;82(6):491-496

87. Natavio MF, Taylor D, Lewis RA, et al. Temporal changes in cervical mucus after insertion of the levonorgestrel-releasing intrauterine system. Contraception. 2013;87(4):426-431.

88. Andersson K, Odlind V, Rybo G. Levonorgestrel-releasing and copperreleasing (Nova T) IUDs during five years of use: a randomized comparative trial. Contraception. 1994;49(1):56-72.

89. Fraser IS. Non-contraceptive health benefits of intrauterine hormonal systems. Contraception. 2010;82(5):396-403.

90. Bednarek PH, Jensen JT. Safety, efficacy and patient acceptability of the contraceptive and non-contraceptive uses of the LNG-IUS. Int $J$ Womens Health. 2010;1:45-58.

91. Qiu J, Cheng J, Wang Q, Hua J. Levonorgestrel-releasing intrauterine system versus medical therapy for menorrhagia: a systematic review and meta-analysis. Med Sci Monit. 2014;20:1700-1713.

92. Kiseli M, Kayikcioglu F, Evliyaoglu O, Haberal A. Comparison of therapeutic efficacies of norethisterone, tranexamic acid and levonorgestrel-releasing intrauterine system for the treatment of heavy menstrual bleeding: a randomized controlled study. Gynecol Obstet Invest. 2016. Epub 2016 Mar 8.

93. Kaunitz AM, Bissonnette F, Monteiro I, Lukkari-Lax E, Muysers C, Jensen JT. Levonorgestrel-releasing intrauterine system or medroxyprogesterone for heavy menstrual bleeding: a randomized controlled trial. Obstet Gynecol. 2010;116(3):625-632.

94. Kaunitz AM, Inki P. The levonorgestrel-releasing intrauterine system in heavy menstrual bleeding: a benefit-risk review. Drugs. 2012;72(2):193-215.
95. Ganz ML, Shah D, Gidwani R, et al. The cost-effectiveness of the levonorgestrel-releasing intrauterine system for the treatment of idiopathic heavy menstrual bleeding in the United States. Value Health. 2013;16(2):325-333.

96. Park DS, Kim ML, Song T, et al. Clinical experiences of the levonorgestrel-releasing intrauterine system in patients with large symptomatic adenomyosis. Taiwan J Obstet Gynecol. 2015;54(4): 412-415.

97. Marjoribanks J, Lethaby A, Farquhar C. Surgery versus medical therapy for heavy menstrual bleeding. Cochrane Database Syst Rev. 2016; 1:CD003855.

98. Yang BQ, Xu JH, Teng YC. Levonorgestrel intrauterine system versus thermal balloon ablation for the treatment of heavy menstrual bleeding: a meta-analysis of randomized controlled trials. Exp Ther Med. 2015;10(5):1665-1674.

99. Gupta JK, Daniels JP, Middleton LJ, et al; ECLIPSE Collaborative Group. A randomized controlled trial of the clinical effectiveness and cost-effectiveness of the levonorgestrel-releasing intrauterine system in primary care against standard treatment for menorrhagia: the ECLIPSE trial. Health Technol Assess. 2015;19(88):i-xxv,1-118.

100. Kaunitz AM, Bissonnette F, Monteiro I, Lukkari-Lax E, DeSanctis Y, Jensen J. Levonorgestrel-releasing intrauterine system for heavy menstrual bleeding improves hemoglobin and ferritin levels. Contraception. 2012;86(5):452-457.

101. Ji F, Yang XH, Ai Xing Zi AL, Ha Ni Ke Zi TX, He Y, Ding Y. Role of levonorgestrel-releasing intrauterine system in dysmenorrhea due to adenomyosis and the influence on ovarian function. Clin Exp Obstet Gynecol. 2014;41(6):677-680.

102. Imai A, Matsunami K, Takagi H, Ichigo S. Levonorgestrel-releasing intrauterine device used for dysmenorrhea: five-year literature review. Clin Exp Obstet Gynecol. 2014;41(5):495-498.

103. Bahamondes L, Petta CA, Fernandes A, Monteiro I. Use of the levonorgestrel-releasing intrauterine system in women with endometriosis, chronic pelvic pain and dysmenorrhea. Contraception. 2007;75(6 suppl): S134-S139.

104. Sheng J, Zhang WY, Zhang JP, Lu D. The LNG-IUS study on adenomyosis: a 3-year follow-up study on the efficacy and side effects of the use of levonorgestrel intrauterine system for the treatment of dysmenorrhea associated with adenomyosis. Contraception. 2009;79(3):189-193.

105. Lan S, Ling L, Jianhong Z, Xijing J, Lihui W. Analysis of the levonorgestrel-releasing intrauterine system in women with endometriosis. J Int Med Res. 2013;41(3):548-558.

106. Petta CA, Ferriani RA, Abrao MS, et al. Randomized clinical trial of a levonorgestrel-releasing intrauterine system and a depot GnRH analogue for the treatment of chronic pelvic pain in women with endometriosis. Hum Reprod. 2005;20(7):1993-1998.

107. Abou-Setta AM, Houston B, Al-Inany HG, Farquhar C. Levonorgestrelreleasing intrauterine device (LNG-IUD) for symptomatic endometriosis following surgery. Cochrane Database Syst Rev. 2013;1:CD005072.

108. Wan YL, Holland C. The efficacy of levonorgestrel intrauterine systems for endometrial protection: a systematic review. Climacteric. 2011;14(6):622-632.

109. Somboonporn W, Panna S, Temtanakitpaisan T, Kaewrudee S, Soontrapa S. Effects of the levonorgestrel-releasing intrauterine system plus estrogen therapy in perimenopausal and postmenopausal women: systematic review and meta-analysis. Menopause. 2011;18(10):1060-1066.

110. Dominick S, Hickey M, Chin J, Su HI. Levonorgestrel intrauterine system for endometrial protection in women with breast cancer on adjuvant tamoxifen. Cochrane Database Syst Rev. 2015;12:CD007245.

111. Kim MK, Seong SJ, Kim JW, et al. Management of endometrial hyperplasia with a levonorgestrel-releasing intrauterine system: a Korean gynecologic-oncology group study. Int $J$ Gynecol Cancer. 2016;26(4):711-715.

112. Luo L, Luo B, Zheng Y, Zhang H, Li J, Sidell N. Levonorgestrelreleasing intrauterine system for atypical endometrial hyperplasia. Cochrane Database Syst Rev. 2013;6:CD009458. 
113. El Behery MM, Saleh HS, Ibrahiem MA, Kamal EM, Kassem GA, Mohamed Mel S. Levonorgestrel-releasing intrauterine device versus dydrogesterone for management of endometrial hyperplasia without atypia. Reprod Sci. 2015;22(3):329-334.

114. Kim MK, Seong SJ, Kim YS, et al. Combined medroxyprogesterone acetate/levonorgestrel-intrauterine system treatment in young women with early-stage endometrial cancer. Am J Obstet Gynecol. 2013;209(4):358.e1-e4.

115. Morelli M, Di Cello A, Venturella R, Mocciaro R, D’Alessandro P, Zullo F. Efficacy of the levonorgestrel intrauterine system (LNG-IUS) in the prevention of the atypical endometrial hyperplasia and endometrial cancer: retrospective data from selected obese menopausal symptomatic women. Gynecol Endocrinol. 2013;29(2):156-159.

116. Ørbo A, Arnes M, Vereide AB, Straume B. Relapse risk of endometrial hyperplasia after treatment with the levonorgestrel-impregnated intrauterine system or oral progestogens. BJOG. 2015. Epub 2015 Dec 2.

117. Turok DK, Sanders JN, Thompson IS, Royer PA, Eggebroten J, Gawron LM. Preference for and efficacy of oral levonorgestrel for emergency contraception with concomitant placement of a levonorgestrel IUD: a prospective cohort study. Contraception. 2016;93(6):526-532.

118. Eisenberg DL, Schreiber CA, Turok DK, et al; ACCESS IUS Investigators. Three-year efficacy and safety of a new 52-mg levonorgestrelreleasing intrauterine system. Contraception. 2015;92(1):10-16.

119. Creinin MD, Jansen R, Starr RM, et al. Levonorgestrel release rates over 5 years with the Liletta ${ }^{\circledR} 52-\mathrm{mg}$ intrauterine system. Contraception. Epub 2016.

120. Bahamondes MV, Monteiro I, Castro S, Espejo-Arce X, Bahamondes L. Prospective study of the forearm bone mineral density of long-term users of the levonorgestrel-releasing intrauterine system. Hum Reprod. 2010;25(5):1158-1164.

121. Mawet M, Nollevaux F, Nizet D, et al. Impact of a new levonorgestrel intrauterine system, Levosert, on heavy menstrual bleeding: results of a one-year randomized controlled trial. Eur J Contracept Reprod Health Care. 2014;19(3):169-179.

122. Nelson A, Apter D, Hauck B, et al. Two low-dose levonorgestrel intrauterine contraceptive systems: a randomized controlled trial. Obstet Gynecol. 2013;122(6):1205-1213.
123. Apter D, Gemzell-Danielsson K, Hauck B, Rosen K, Zurth C Pharmacokinetics of two low-dose levonorgestrel-releasing intrauterine systems and effects on ovulation rate and cervical function: pooled analyses of phase II and III studies. Fertil Steril. 2014;101(6): 1656-62.

124. Gemzell-Danielsson K, Buhling KJ, Dermout SM, Lukkari-Lax E, Montegriffo E, Apter D. A phase III, single-arm study of LNG-IUS 8, a low-dose levonorgestrel intrauterine contraceptive system (total content $13.5 \mathrm{mg}$ ) in postmenarcheal adolescents. Contraception. 2016; 93(6):507-512.

125. Gemzell-Danielsson K, Schellschmidt I, Apter D. A randomized, phase II study describing the efficacy, bleeding profile, and safety of two low-dose levonorgestrel-releasing intrauterine contraceptive systems and Mirena. Fertil Steril. 2012;97(3):616-622.

126. Al-Ashwal RH, Aziz NA, Nooh SM. Development of a smart IUD launcher for prevention of uterine perforation. Biomed Tech (Berl). 2016. Epub 2016 Feb 25.

127. Potter J, Rubin SE, Sherman P. Fear of intrauterine contraception among adolescents in New York City. Contraception. 2014;89(5):446-450.

128. Moos MK, Dunlop AL, Jack BW, et al. Healthier women, healthier reproductive outcomes: recommendations for the routine care of all women of reproductive age. Am J Obstet Gynecol. 2008;199(6 suppl 2): S280-S289.

129. Foster DG, Biggs MA, Ralph LJ, Arons A, Brindis CD. Family planning and life planning reproductive intentions among individuals seeking reproductive health care. Womens Health Issues. 2008;18(5): 351-359.

130. Nelson AL, Shabaik S, Xandre P, Awaida JY. Reproductive life planning and preconception care 2015: attitudes of English-speaking family planning patients. $J$ Womens Health (Larchmt). 2016. Epub 2016 Mar 14.

131. Borrero S, Nikolajski C, Steinberg JR, et al. "It just happens": a qualitative study exploring low-income women's perspectives on pregnancy intention and planning. Contraception. 2015;91(2):150-156

132. The National Campaign to Prevent Teen and Unplanned Pregnancy [homepage on the Internet]. Available from: https://thenationalcam paign.org/. Accessed June 28, 2016.
Open Access Journal of Contraception

\section{Publish your work in this journal}

Open Access Journal of Contraception is an international, peerreviewed, open access, online journal, publishing original research, reports, reviews and commentaries on all areas of contraception. In addition to clinical research, demographics and health-related aspects, the journal welcomes new findings in animal and preclinical studies

\section{Dovepress}

relating to understanding the biological mechanisms and practical development of new contraceptive agents. The manuscript management system is completely online and includes a very quick and fair peer-review system. Visit http://www.dovepress.com/testimonials.php to read real quotes from published authors. 